DE

M E D I C I N A

T R O P I C A L

$\mathrm{DE}$

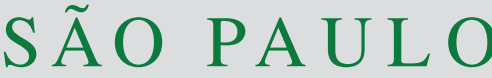

JOURNAL OF THE SÃO PAULO INSTITUTE OF TROPICAL MEDICINE

\section{Analysis of mitochondrial enzymatic activity in blood lymphomonocyte fractions during infection with different Trypanosoma cruzi strains}

\author{
Alejandra L. Báez ${ }^{\circledR 1}$, María S. Lo Presti' ${ }^{1}$, Paola C. Bazán', Mariana Strauss ${ }^{1}$, \\ Daniela A. Velázquez López', Noemí Miler', Héctor W. Rivarola', Patricia A. \\ Paglini-Oliva ${ }^{1}$
}

${ }^{1}$ Universidad Nacional de Córdoba, Facultad de Ciencias Médicas, Instituto de Investigaciones en Ciencias de la Salud, Centro de Estudios e Investigación de la Enfermedad de Chagas y Leishmaniasis, INICSA-CONICET, Córdoba, Argentina

Correspondence to: Alejandra L. Báez Universidad Nacional de Córdoba, Facultad de Ciencias Médicas, Instituto de Investigaciones en Ciencias de la Salud, Centro de Estudios e Investigación de la Enfermedad de Chagas y Leishmaniasis, INICSA-CONICET, Santa Rosa, 1085, X5000ESU, Córdoba, Argentina

Tel: +54 3514332020

Fax: +543514332020

E-mail: alejandralidiab @ hotmail.com

Received: 25 September 2019

Accepted: 2 December 2019

\section{INTRODUCTION}

Chagas disease is a common cause of cardiomyopathy resulting in premature or sudden death. It is caused by the protozoan Trypanosoma cruzi (T. cruzi), and affects between 10 and 18 million people in the Americas and is becoming a health problem in non-endemic countries due to migratory movements ${ }^{1-3}$.

When T. cruzi enters cells, it produces inflammatory reactions that stimulate the production of cytokines and free radicals that, through their products (nitric oxide, reactive oxygen species, etc.) try to control parasite reproduction, but are ultimately responsible for tissue damage. Cardiomyocytes response to the oxidative stress lead to important cellular changes, fundamentally targeting mitochondria ${ }^{4,5}$. All the cells, including cardiomyocytes, are capable of generating reactive oxygen species (ROS). The mitochondrial enzymes xanthinoxidase and NADPH oxidase and the respiratory chain in which oxygen can activate superoxide radicals by a non-enzymatic process, are the main source of ROS when physiological functions are normal. ROS basal level is produced and maintained by normal cells and ROS production increases when the functioning of the respiratory chain is changed ${ }^{6-8}$. 
We have previously demonstrated that patients with heart failure have high ROS levels and respiratory chain as well as mitochondrial structure changes, not only in cardiac cells but also in skeletal muscle ${ }^{9}$. We have also found changes in cardiac and skeletal muscle mitochondria regarding their function and structure ${ }^{10}$ in experimental models during the acute stage of $T$. cruzi infection ${ }^{11}$, chronic stage ${ }^{12}$ and indeterminate phase ${ }^{13}$ with important variations depending on the strain of $T$. cruzi used to infect the host. Increased oxidative stress and mitochondrial damage have also been demonstrated in blood samples of patients with advanced Chagas' heart disease ${ }^{14}$.

T. cruzi invasion produces a generalized inflammatory process as the parasite can be found in many different tissues $^{15}$. In the present research, we studied the enzymatic activity of the respiratory chain (CI-CIV) and the citrate synthase of mitochondria from the lymphomonocyte fraction obtained from experimental models infected with different $T$. cruzi strains. We believed that mitochondrial changes detected by a simple blood extraction, could act as an early marker of disease, especially in the indeterminate phase of Chagas disease.

\section{MATERIALS AND METHODS}

\section{Infection}

Female and male three month old albino Swiss mice weighting $30 \pm 1 \mathrm{~g}(\mathrm{n}=120)$ were used, as follows: Thirty non-infected mice were used as the control group, 30 mice were inoculated intraperitoneally with 50 trypomastigote forms of T. cruzi Tulahuen strain (lineage II e); 29 mice were infected with 50 trypomastigote forms of the Lucky isolate, a mixture of lineages II and IV ${ }^{15} ; 31$ mice were inoculated with 50 trypomastigote forms of the SGO Z12 isolate.

Blood samples collected from the tail of the animals were evaluated by a Neubauer hemocytometer to determine parasitemia twice a week in all the groups. This process began seven days after the infection. Our experiments respected the Guide for the Care and Use of Laboratory Animals ${ }^{16,17}$.

\section{Sample collection and procedure for isolation of lymphocytes and mitochondria}

Blood samples were collected in $\mathrm{K}_{3}$ EDTA $(1.5 \mathrm{mg} / \mathrm{mL}$ blood) tubes for the isolation of lymphocytes by the Isopaque-Ficoll technique ${ }^{18}$ on days 35,75 and 365 postinfection (p.i.), corresponding to the acute, indeterminate and chronic stages of the experimental infection.

The procedure of lymphocytes washing to remove platelets was performed using a Pasteur pipette and transferring the lymphocyte layer to a centrifuge tube, adding at least 3 volumes $(6 \mathrm{~mL})$ of balanced salt solution. Cells were suspended by gentle aspirations performed with the Pasteur pipette and then solutions were centrifuged twice at $60-100 \times \mathrm{g}$ for $10 \mathrm{~min}$ at $18-20{ }^{\circ} \mathrm{C}$ for later supernatant removal. Lymphocytes were then suspended in Hank medium ( $\mathrm{pH} \mathrm{7.4)} \mathrm{and} \mathrm{mitochondria} \mathrm{were} \mathrm{isolated}$ as previously described ${ }^{10-13}$ on days 35,75 and 365 postinfection. Briefly, blood aliquots were homogenized in equal volumes of ice-cold $10 \mathrm{mM}$ Hepes buffer, $\mathrm{pH}$ 7.2, containing $420 \mathrm{mM}$ mannitol, $140 \mathrm{mM}$ sucrose, $2 \mathrm{mM}$ EGTA, and $2 \mathrm{mg} / \mathrm{mL}$ BSA (fatty acid free). Thereafter, they were subjected to sequential centrifugation at 800 and $8100 \mathrm{x} \mathrm{g}$, each for $15 \mathrm{~min}$ at $4{ }^{\circ} \mathrm{C}$. The pellet containing mitochondria was washed, resuspended in the isolation buffer and then stored at $-80^{\circ} \mathrm{C}$. The protein concentration was determined by the Bradford method ${ }^{19}$.

\section{Determination of the enzymatic activity of the respiratory complex and citrate synthase}

The enzymatic activity of the respiratory complexes I to IV (CI-CIV) and the citrate synthase was determined by spectrophotometric analysis ${ }^{10-13,20-22}$. The protein concentrations were determined by the Bradford method ${ }^{19}$. Each of the experiments was carried out in $1 \mathrm{~mL}$ final volume with $30-40 \mathrm{mg}$ of mitochondrial protein/ per pellet, for complexes I and II; 20-30 mg of mitochondrial protein/ per pellet, for complex III and $15 \mathrm{mg}$ of mitochondrial protein/ per pellet for complex IV. Linear absorbance changes were measured for $3 \mathrm{~min}$.

\section{Histopathological studies}

The heart and sections of hind legs skeletal muscles (rectus femoris, sartorius, vastus medialis and lateralis muscles) were removed from infected mice on days 35,75 and 365 p.i., fixed in buffered (pH 7.0) $10 \%$ formaldehyde, and embedded in paraffin. Each heart was cut horizontally from the apex to the auricles into $5 \mu \mathrm{m}$ sections and skeletal muscles were also cut horizontally into $5 \mu \mathrm{m}$ sections. All the sections were stained with hematoxylin-eosin. A total of 50 slices from each group was studied with a $40 \mathrm{X}$ objective.

\section{Statistical analysis}

The results are shown as mean \pm standard error. Data were analyzed by ANOVA and multiple comparisons by the Fisher exact test. The level of the significance was set at $\mathrm{p}<0.05$ for all the experiments. 


\section{RESULTS}

\section{Detection of parasites in blood samples}

The detection of parasites in blood samples was carried out to assess the infection rate. Tulahuen and SGO Z12 infected groups presented the highest parasite concentrations by day 14 p.i. and the Lucky isolate infected group by day 28 p.i. Tulahuen-infected mice presented parasitemia clearance by day 42 and the SGO Z12 and the Lucky infected groups by day 49 .

\section{Enzymatic activity of citrate synthase and Cl-CIV complexes}

The enzymes activities of citrate synthase and CI-CIV complexes of mitochondria obtained from the lymphomonocyte fraction of blood samples were determined 35 days post infection (acute phase), 75 (indeterminate phase), and 365 days post infection (chronic phase), as previously described ${ }^{11-13}$.

During the acute phase of the infection, the citrate synthase enzymatic activity remained similar to the control group for Tulahuen- and SGO Z12-infected groups, and was significantly reduced in the Lucky group $(\mathrm{p}<0.05)$; during the indeterminate phase, the enzymatic activity increased in the SGO-infected group $(\mathrm{p}<0.05)$ and in the chronic phase, its activity was higher in the Tulahuen-infected mice and reduced in the SGO-infected ones $(\mathrm{p}<0.05)$ (Table 1).
CI-CIV changed their enzymatic activities in different manners according to the stage of the infection and to the parasite strain used in the infection (Table 1).

In the indeterminate phase without disease, CI enzymatic activity was changed in all the infected groups; CII was different with respect to the control group in the Tulahuen and SGO Z12 groups; CIII was different in the Tulahuen group and Complex IV was the one with the highest stability when compared to the controls, in the three studied groups.

\section{Histopathological studies}

Figure 1 show hearts from the Tulahuen, SGO Z12 and Lucky isolate-infected group extracted on days 35, 75 and 365 d.p.i. It is noteworthy that during the acute phase of the infection and depending of the strain or isolate, hearts presented inflammatory infiltrates (Tulahuen), while SGO Z12 and Lucky isolate hearts presented only mononuclear infiltrates. During the indeterminate phase ( 75 d.p.i.), mild inflammatory infiltrates were detected in the three groups.

Hearts from the Tulahuen-infected group studied on 365 d.p.i. presented fiber fragmentation, hearts from the SGO Z12-infected group showed fiber fragmentation and mononuclear inflammatory infiltrates, while the Lucky group presented only mononuclear inflammatory infiltrates.

Figure 2 shows skeletal muscles from Tulahuen infected mice presenting inflammatory infiltrates and amastigotes nests by day 35 d.p.i; SGO Z12 and the Lucky isolate-infected

Table 1 - Mitochondrial enzymatic activity ( $\mu$ /fmoles $\mathrm{min}^{-1} \mathrm{mg}^{-1}$ protein) of lymphomonocyte fractions obtained from non-infected $(n=30)$, Tulahuen-infected $(n=30)$, Lucky-infected $(n=29)$ and SGO Z12- infected $(n=31)$ mice on 35,75 and 365 days postinfection.

\begin{tabular}{|c|c|c|c|c|c|c|c|c|c|c|}
\hline $\begin{array}{l}\text { Enzymatic activity } \\
\left(\mu / f \text { moles } \mathrm{min}^{-1} \mathrm{mg}^{-1}\right. \\
\text { protein) }\end{array}$ & $\begin{array}{l}\text { Non-Infected (Control) } \\
\begin{array}{l}\left({ }^{*}\right) 35 \text { d.p.i., } \\
(\cdot) 75 \text { d.p.i., } \\
\text { (+) } 365 \text { d.p.i. }\end{array}\end{array}$ & $\begin{array}{l}\text { Tulahuen } \\
35 \text { d.p.i. }\end{array}$ & $\begin{array}{l}\text { Tulahuen } \\
75 \text { d.p.i. }\end{array}$ & $\begin{array}{l}\text { Tulahuen } \\
365 \text { d.p.i. }\end{array}$ & $\begin{array}{l}\text { Lucky } \\
35 \text { d.p.i. }\end{array}$ & $\begin{array}{l}\text { Lucky } \\
75 \text { d.p.i. }\end{array}$ & $\begin{array}{l}\text { Lucky } \\
365 \text { d.p.i. }\end{array}$ & $\begin{array}{c}\text { Z12 } \\
35 \text { d.p.i. }\end{array}$ & $\begin{array}{c}\text { Z12 } \\
75 \text { d.p.i. }\end{array}$ & $\begin{array}{c}\text { Z12 } \\
365 \text { d.p.i. }\end{array}$ \\
\hline Citrate synthase & $\begin{array}{l}0.25 \pm 0.05^{\mathrm{a}, \mathrm{b}\left({ }^{*}\right)} \\
0.14 \pm 0.01^{\mathrm{a}(\cdot)} \\
0.29 \pm 0.03^{\mathrm{b}(+)}\end{array}$ & $\begin{array}{c}0.69 \pm \\
0.44^{b}\end{array}$ & $\begin{array}{c}0.16 \pm \\
0.01^{\mathrm{a}}\end{array}$ & $\begin{array}{c}0.68 \pm \\
0.04^{c}\end{array}$ & $\begin{array}{l}0.03 \pm \\
0.003^{c}\end{array}$ & $\begin{array}{c}0.10 \pm \\
0.01^{\mathrm{a}}\end{array}$ & $\begin{array}{l}0.25 \pm \\
0.02^{\mathrm{b}}\end{array}$ & $\begin{array}{l}0.30 \pm \\
0.01^{\mathrm{a}, \mathrm{b}}\end{array}$ & $\begin{array}{c}0.76 \pm \\
0.19^{b}\end{array}$ & $\begin{array}{l}0.12 \pm \\
0.004^{\mathrm{a}}\end{array}$ \\
\hline Complex I & $\begin{array}{c}0.0017 \pm 0.007^{a(*)} \\
0.04 \pm 0.003^{c(\cdot)} \\
0.08 \pm 0.01^{b(+)}\end{array}$ & $\begin{array}{l}0.15 \pm \\
0.03^{c}\end{array}$ & $\begin{array}{l}0.001 \pm \\
0.0005^{\mathrm{a}}\end{array}$ & $\begin{array}{c}0.15 \pm \\
0.02^{\mathrm{c}}\end{array}$ & $\begin{array}{c}0.01 \pm \\
0.0015^{a}\end{array}$ & $\begin{array}{l}0.01 \pm \\
0.003^{b}\end{array}$ & $\begin{array}{l}0.10 \pm \\
0.03^{b}\end{array}$ & $\begin{array}{l}0.09 \pm \\
0.01^{b}\end{array}$ & $\begin{array}{c}0.0006 \pm \\
0.0002^{\mathrm{a}}\end{array}$ & $\begin{array}{l}0.01 \pm \\
0.003^{\mathrm{a}}\end{array}$ \\
\hline Complex II (fmoles) & $\begin{array}{c}19.64 \pm 4.85^{\mathrm{a}\left({ }^{(*)}\right.} \\
49.61 \pm 28.99^{\mathrm{b}(\cdot)} \\
1372.57 \pm 630.52^{\mathrm{a}, \mathrm{b}(+)}\end{array}$ & $\begin{array}{c}135.78 \pm \\
59.31^{\mathrm{b}}\end{array}$ & $\begin{array}{c}2.25 \pm \\
0.98^{\mathrm{a}}\end{array}$ & $\begin{array}{c}1609.03 \pm \\
856.89^{\mathrm{b}}\end{array}$ & $\begin{array}{c}10.03 \pm \\
1.82^{\mathrm{a}}\end{array}$ & $\begin{array}{c}22.62 \pm \\
7.63^{a, b}\end{array}$ & $\begin{array}{c}59.49 \pm \\
22.15^{\mathrm{a}}\end{array}$ & $\begin{array}{l}92.41 \pm \\
30.85^{a, b}\end{array}$ & $\begin{array}{c}4.64 \pm \\
2.44^{\mathrm{a}}\end{array}$ & $\begin{array}{c}151.41 \pm \\
84.69^{a, b}\end{array}$ \\
\hline Complex III & $\begin{array}{l}0.36 \pm 0.04^{\mathrm{b}\left({ }^{*}\right)} \\
0.16 \pm 0.06^{\mathrm{b}(\cdot)} \\
0.22 \pm 0.10^{\mathrm{a}(+)}\end{array}$ & $\begin{array}{c}0.06 \pm \\
0.01^{a}\end{array}$ & $\begin{array}{c}0.01 \pm \\
0.0004^{a}\end{array}$ & $\begin{array}{c}0.28 \pm \\
0.14^{\mathrm{a}}\end{array}$ & $\begin{array}{l}0.31 \pm \\
0.03^{b}\end{array}$ & $\begin{array}{l}0.07 \pm \\
0.03^{\mathrm{a}, \mathrm{b}}\end{array}$ & $\begin{array}{c}0.05 \pm \\
0.01^{a}\end{array}$ & $\begin{array}{c}0.06 \pm \\
0.01^{\mathrm{a}}\end{array}$ & $\begin{array}{l}0.09 \pm \\
0.01^{\mathrm{a}, \mathrm{b}}\end{array}$ & $\begin{array}{l}0.71 \pm \\
0.17^{\mathrm{b}}\end{array}$ \\
\hline Complex IV & $\begin{array}{c}0.41 \pm 0.06^{\mathrm{a}\left({ }^{(*)}\right)} \\
0.16 \pm 0.06^{\mathrm{b}(\cdot)} \\
0.02 \pm 0.004^{\mathrm{a}(+)}\end{array}$ & $\begin{array}{c}0.53 \pm \\
0.33^{\mathrm{a}}\end{array}$ & $\begin{array}{l}0.11 \pm \\
0.06^{a, b}\end{array}$ & $\begin{array}{l}0.37 \pm \\
0.18^{a, b}\end{array}$ & $\begin{array}{c}0.02 \pm \\
0.01^{\mathrm{a}}\end{array}$ & $\begin{array}{l}0.08 \pm \\
0.04^{\mathrm{a}, \mathrm{b}}\end{array}$ & $\begin{array}{l}0.37 \pm \\
0.27^{a, b}\end{array}$ & $\begin{array}{l}1.61 \pm \\
0.37^{b}\end{array}$ & $\begin{array}{c}0.03 \pm \\
0.01^{\mathrm{a}}\end{array}$ & $\begin{array}{c}0.78 \pm \\
0.14^{\mathrm{b}}\end{array}$ \\
\hline
\end{tabular}

The results are expressed as mean \pm standard error. The significance level was set at $p<0.05$ for all cases, different letters $(a, b, c)$ indicate significant differences. 

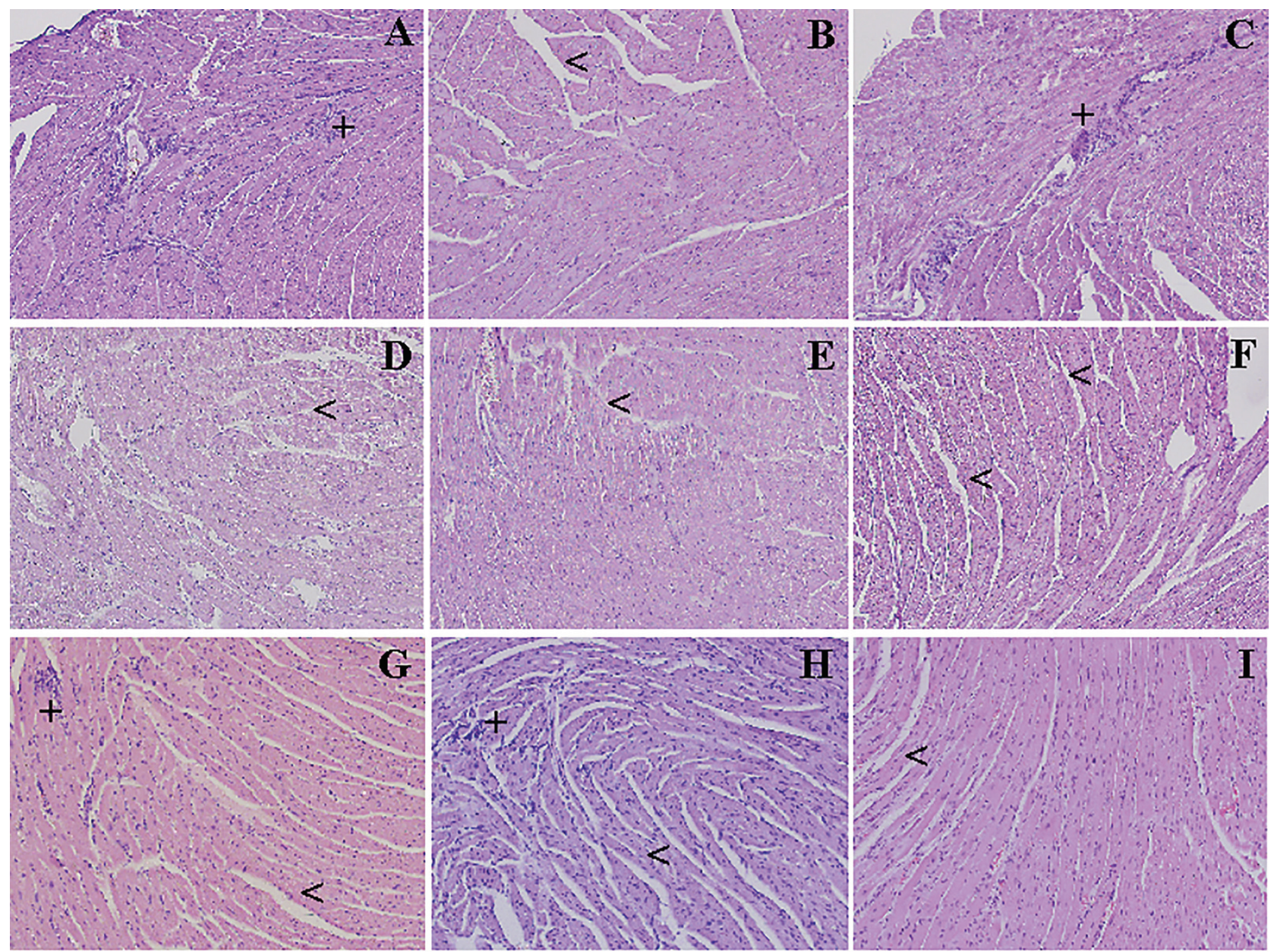

Figure 1 - Cardiac histological sections from the different groups: (A: 35 days p.i., B: 75 days p.i., C: 365 days p.i.) x 200 , Tulahueninfected mice. (D: 35 days p.i., E: 75 days p.i., F: 365 days p.i.) SGO Z12-infected group, x 200. (G: 35 days p.i., H: 75 days p.i., I: 365 days p.i.) Lucky-infected group, x 200. +: presence of inflammatory infiltrates; <: presence of fiber fragmentation.

mice have also shown inflammatory infiltrates. During the indeterminate phase (75 d.p.i.), the inflammatory infiltrates persisted in the three groups. In the chronic stage (365 d.p.i.) the Lucky and SGO Z12 groups presented inflammatory infiltrates, while the Tulahuen-infected group presented not only inflammatory infiltrates but also amastigotes nests.

\section{DISCUSSION}

Reactive oxygen species (ROS) have a direct effect on chronic inflammatory processes and have been associated to the genesis of cardiac insufficiency and remodeling ${ }^{6,7}$. It has been proposed that the response of cardiac cells to oxidative stress produces progressive cellular changes targeting mitochondria ${ }^{8,23-25}$, demonstrating that the oxidative stress triggers mitochondrial mechanisms towards apoptosis that would be involved in the pathophysiology of ischemia and heart failure ${ }^{25}$.

However, it should be noted that T. cruzi entry does not only involve myocardial cells; it has been demonstrated that the parasites use skeletal muscles as reservoirs throughout the course of infection, leading to functional and structural mitochondrial changes, and permanent skeletal muscle alterations ${ }^{12}$ so that $T$. cruzi invasion produces a generalized inflammatory process as the parasite can be found in many different tissues ${ }^{15}$.

In the present study, we evaluated changes in the activity of one enzyme from the Krebs cycle as well as changes in complex I-IV of the mitochondrial respiratory chain in blood lymphomonocyte fractions triggered by infection with one T. cruzi strain and two T. cruzi isolates during the acute, indeterminate and chronic phases, to demonstrate that this infection involves changes in many structures of cellular energy metabolism that remain throughout the different phases. These changes may be important because they probably appear before clinical manifestations and could be used to prevent the progression of chagasic disease.

During the acute phase of the infection, the citrate synthase enzymatic activity remained similar to the control group in the Tulahuen and SGO Z12-infected groups, and 

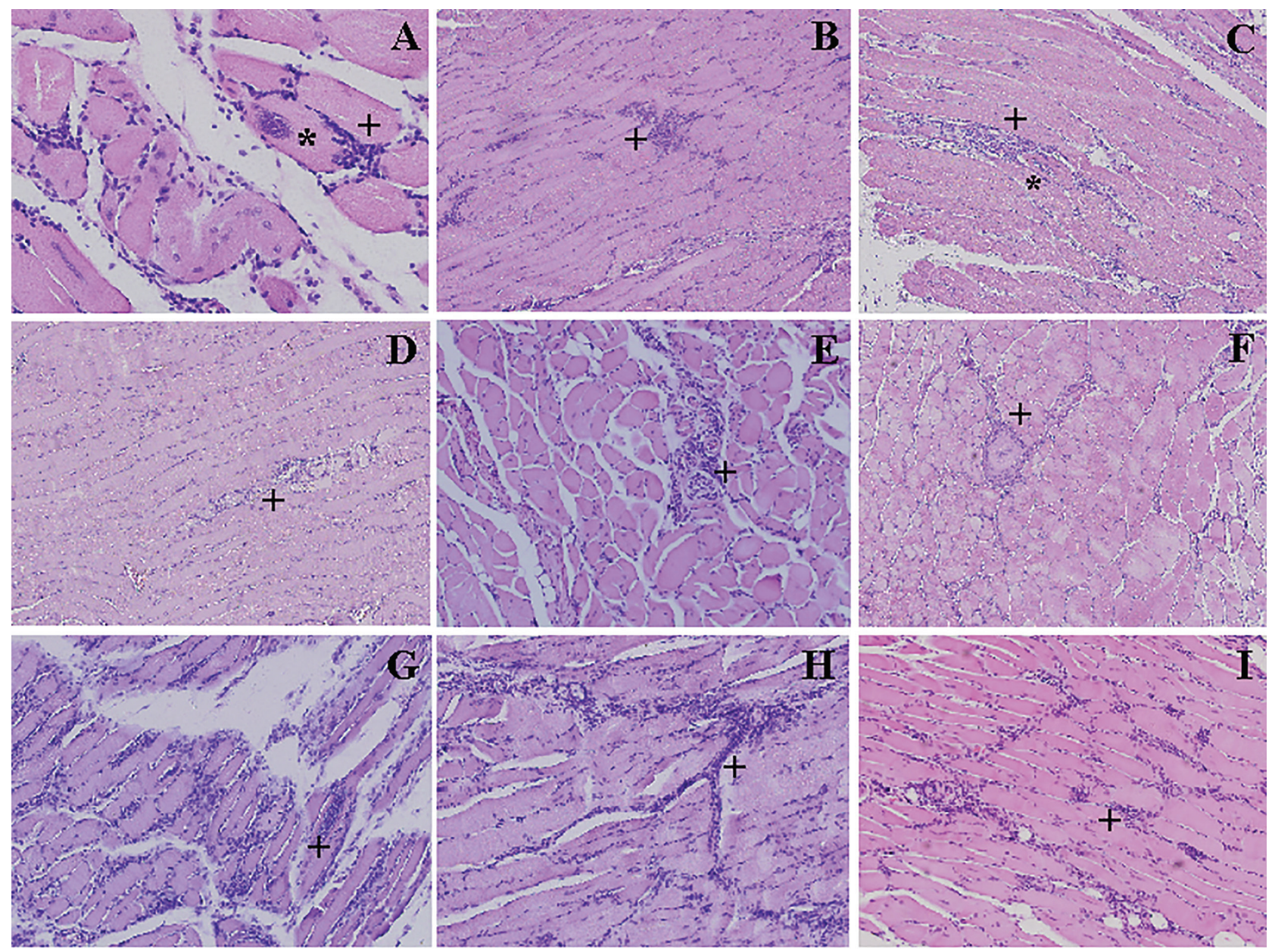

Figure 2 - Skeletal muscle histological sections from the different groups: (A: 35 days p.i.) 400x (B: 75 days p.i., C: 365 days p.i.) x 200 , Tulahuen-infected mice. (D: 35 days p.i., E: 75 days p.i., F: 365 days p.i.) SGO Z12-infected group, x 200. (G: 35 days p.i., H: 75 days p.i., I: 365 days p.i.) Lucky-infected group, $x$ 200. +: presence of inflammatory infiltrates; *: presence of amastigotes nests.

was significantly reduced in the Lucky group $(\mathrm{p}<0.05)$; during the indeterminate phase, the citrate synthase enzymatic activity increased in the SGO Z12-infected group $(\mathrm{p}<0.05)$ and in the chronic phase, its activity was changed in the Tulahuen and SGO Z12-infected mice $(\mathrm{p}<0.05)$.

CI-CIV complexes modified their enzymatic activities in different manners according to the stage of the infection and to the parasite strain used in the experimental infection. It is interesting that in the indeterminate phase without disease, the CI enzymatic activity was changed in all infected groups; CII was different to the control group in the Tulahuen and SGO Z12 groups; CIII was different in the Tulahuen group and Complex IV was the complex with the highest stability when compared to the controls, in the three studied groups.

The histopathological studies of heart and skeletal muscles found inflammatory infiltrates of different magnitudes according to the isolate used to infect mice and the stage of the infection that was certainly involved in the triggering of the increased oxidative stress, leading to effects upon the mitochondrial enzymatic activity.
The results of the present study show that $T$. cruzi infection in all phases damages mitochondrial enzymes activities in blood lymphomonocyte fractions, and that during the indeterminate stage CI, CII and CIII complex activities were modified in different manners and magnitudes depending on the T. cruzi strain or isolate involved in the infection, making them interesting tools to determine Chagas disease progression before the onset of clinical signs and symptoms. These mitochondrial enzymes alterations can be detected by a simple blood extraction, suggesting that they can act as disease markers, especially in the indeterminate phase.

\section{AUTHORS' CONTRIBUTIONS}

All the authors were involved in the conception and design of the study, the analysis and interpretation of data, drafting the article and revising it critically regarding the scientific content and the all approved the version to be published. ALB, DAVL and MSLP carried 
out the experiments; MS and PCB were responsible for the statistical analysis; NM and HWR contributed with the writing and revision of the manuscript; PPO was responsible for the protocol design and is the research senior investigator.

\section{ETHICAL APPROVAL}

All applicable international, national, and/or institutional guidelines for the care and use of animals were followed (NIH, 1996).

\section{FUNDING}

This research did not receive any specific grant from funding agencies in the public, commercial and not-forprofit sectors.

\section{REFERENCES}

1. Schmunis GA, Yadon ZE. Chagas disease: a Latin American health problem becoming a world health problem. Acta Trop. 2010;115:14-21.

2. Perez CJ, Lymbery AJ, Thompson RC. Reactivation of Chagas disease: implications for global health. Trends Parasitol. 2015;31:595-603.

3. World Health Organization. Control of Chagas disease: second report of the WHO Expert Committee. Geneva: WHO; 2002.

4. Marin-Garcia J. Mitochondrial DNA repair: a novel therapeutic target for heart failure. Heart Fail Rev. 2016;21:475-87.

5. Marin-Garcia J. Cell death in the pathogenesis and progression of heart failure. Heart Fail Rev. 2016;21:117-21.

6. Marin-García J, Goldenthal MJ. Mitochondrial centrality in heart failure. Heart Fail Rev. 2008;13:137-50.

7. Marin-García J, Akhmedov AT, Moe GW. Mitochondria in heart failure: the emerging role of mitochondrial dynamics. Heart Fail Rev. 2013;18:439-56.

8. Tsutsui H. Mitochondrial oxidative stress and heart failure. Intern Med. 2006;45:809-13.

9. Guzmán Mentesana G, Báez A, Lo Presti MS, Domínguez R, Córdoba R, Bazán C, et al. Functional and structural alterations of cardiac and skeletal muscle mitochondria in heart failure patients. Arch Med Res. 2014;45:237-46.

10. Báez AL, Reynoso MN, Lo Presti MS, Bazán PC, Strauss M, Miler $\mathrm{N}$, et al. Mitochondrial dysfunction in skeletal muscle during experimental Chagas disease. Exp Mol Pathol. 2015;98:46775.

11. Báez AL, Lo Presti MS, Rivarola HW, Pons P, Fretes R, PagliniOliva P. Trypanosoma cruzi: cardiac mitochondrial alterations produced by two different strains in the acute phase of the infection. Exp Parasitol. 2008;120:397-402.
12. Báez A, Lo Presti MS, Rivarola HW, Mentesana GG, Pons P, Fretes R, et al. Mitochondrial involvement in chronic chagasic cardiomyopathy. Trans R Soc Trop Med Hyg. 2011;105:23946.

13. Báez AL, Lo Presti MS, Fretes R, Díaz C, Pons P, Bazán PC, et al. Chronic indeterminate phase of Chagas' disease: mitochondrial involvement in infection with two strains. Parasitology. 2013;140:414-21.

14. Wen J, Yachelini P, Sembaj A, Manzur RE, Garg NJ. Increased oxidative stress correlates with mitochondrial dysfunction in chagasic patients. Free Radic Biol Med. 2006;41:270-6.

15. Lo Presti MS, Esteves BH, Moya D, Bazán PC, Strauss M, Báez $\mathrm{AL}$, et al. Circulanting Trypanosoma cruzi fractions differ from those found in the tissues of the same host during acute experimental infection. Acta Trop. 2014;133:98-109.

16. Universidad Nacional de Córdoba. Reglamentación para el cuidado y uso de animales de experimentación en dependencia de la Facultad de Ciencias Médicas y Facultad de Odontología, Universidad Nacional de Córdoba. [cited 2019 Dec 2]. Available from: http://secyt.webs.fcm.unc.edu. ar/files/2013/07/Reglamento_para_el_Cuidado_y_Uso_de_ Animales_de_Laboratorio1-2.pdf

17. National Institutes of Health. Division of Research Resources. Animal Resources Program. Guide for the care and use of laboratory animals. Bethesda: NIH; 1996.

18. Boyum A. Isolation of lymphocytes, granulocytes and macrophages. Scand J Immunol. 1976; Suppl 5:9-15.

19. Bradford MM. A rapid and sensitive method for quantitation of microgram quantities of protein utilizing the principle of protein-dye binding. Anal Biochem. 1976;72:248-54.

20. Jarreta D, Orús J, Barrientos A, Miró O, Roig E, Heras M, et al. Mitochondrial function in heart muscle from patients with idiopathic dilated cardiomyopathy. Cardivasc Res. 2000;45:860-5.

21. Trounce IA, Kim YL, Jun AS, Wallace DC. Assessment of mitochondrial oxidative phosphorylation in patient muscle biopsies, lymphoblasts, and transmitochondrial cell lines. Methods Enzymol. 1996;264:484-509.

22. Vyatkina G, Bhatia V, Gerstner A, Papaconstantinou J, Garg N. Impaired mitochondrial respiratory chain and bioenergetics during chagasic cardiomyopathy development. Biochim Biophys Acta. 2004;1689:162-73.

23. Marin-Garcia J, Pi Y, Goldenthal MJ. Mitochondrial-nuclear cross-talk in the aging and failing heart. Cardiovasc Drugs Ther. 2006;20:477-91.

24. Tsutsui H, Kinugawa S, Matsushima S. Mitochondrial oxidative stress and dysfunction in myocardial remodelling. Cardiovasc Res. 2009;81:449-56.

25. Tsutsui H. Novel pathophysiological insights and treatment strategies for heart failure: lessons from mice and patients. Circ J. 2004;68:1095-113. 